\title{
A New Multicriteria Risk Mapping Approach Based on a Multiattribute Frontier Concept
}

\author{
Denys Yemshanov, ${ }^{1,}{ }^{*}$ Frank H. Koch, ${ }^{2, \#}$ Yakov Ben-Haim, ${ }^{3}$ Marla Downing, ${ }^{4}$ Frank Sapio, ${ }^{4}$ \\ and Marty Siltanen ${ }^{1}$
}

\begin{abstract}
Invasive species risk maps provide broad guidance on where to allocate resources for pest monitoring and regulation, but they often present individual risk components (such as climatic suitability, host abundance, or introduction potential) as independent entities. These independent risk components are integrated using various multicriteria analysis techniques that typically require prior knowledge of the risk components' importance. Such information is often nonexistent for many invasive pests. This study proposes a new approach for building integrated risk maps using the principle of a multiattribute efficient frontier and analyzing the partial order of elements of a risk map as distributed in multidimensional criteria space. The integrated risks are estimated as subsequent multiattribute frontiers in dimensions of individual risk criteria. We demonstrate the approach with the example of Agrilus biguttatus Fabricius, a high-risk pest that may threaten North American oak forests in the near future. Drawing on U.S. and Canadian data, we compare the performance of the multiattribute ranking against a multicriteria linear weighted averaging technique in the presence of uncertainties, using the concept of robustness from info-gap decision theory. The results show major geographic hotspots where the consideration of tradeoffs between multiple risk components changes integrated risk rankings. Both methods delineate similar geographical regions of high and low risks. Overall, aggregation based on a delineation of multiattribute efficient frontiers can be a useful tool to prioritize risks for anticipated invasive pests, which usually have an extremely poor prior knowledge base.
\end{abstract}

KEY WORDS: Agrilus biguttatus; multiattribute efficient frontier; multicriteria aggregation; nondominant set; pest risk mapping; robustness to uncertainty

${ }^{1}$ Natural Resources Canada, Canadian Forest Service, Great Lakes Forestry Centre, 1219 Queen Street East, Sault Ste. Marie, Ontario P6A 2E5, Canada.

${ }^{2}$ Department of Forestry and Environmental Resources, North Carolina State University, USA.

\# Present affiliation: USDA Forest Service, Southern Research Station, Eastern Forest Environmental Threat Assessment Center, 3041 Cornwallis Road, Research Triangle Park, NC27709, USA.

${ }^{3}$ Technion, Israel Institute of Technology, Faculty of Mechanical Engineering, Haifa 32000, Israel.

${ }^{4}$ USDA Forest Service, Forest Health Technology Enterprise Team, 2150 Centre Avenue, Building A, Suite 331, Fort Collins, $\mathrm{CO}$, USA.

*Address correspondence to Denys Yemshanov, Natural Resources Canada, Canadian Forest Service, Great Lakes Forestry

\section{INTRODUCTION}

Pest risk maps, which depict the likelihood that an invasive organism will be introduced, established, and have a substantial impact in areas of interest, have been recognized as valuable tools for assisting with strategic decisions regarding the management of biological invasions. ${ }^{(1,2)}$ Federal, state, and provincial land management and regulatory agencies use these maps to prioritize resources

Centre, 1219 Queen Street East, Sault Ste. Marie, Ontario P6A 2E5, Canada; tel: 705-541-5602; fax: 705-541-5700; dyemshan@nrcan.gc.ca. 
for surveillance, quarantine, control, and other activities in response to invasive species. ${ }^{(3-5)}$ Pest risk maps are also powerful visual communication tools that help to raise awareness about new invasive threats and to resolve public concerns caused by regulation. ${ }^{(2)}$

Despite their appeal, constructing risk maps for newly detected or anticipated invaders is a difficult prospect. Often, the amount of knowledge about an emerging pest threat is insufficient to understand basic interactions between the likely drivers of invasion and estimate the long-term establishment potential of an organism. ${ }^{(6)}$ So, instead of applying complex dynamic spread models that require many parameters about the organism's behavior, analysts end up utilizing simple static models ${ }^{(2,6)}$ and estimating individual risk components (such as climatic suitability or susceptible host range) separately using different methodologies and available data. Analysts subsequently face the challenge of aggregating these static realizations of individual risk components into a single, comprehensive pest risk map for use by decisionmakers and stakeholders. ${ }^{(7)}$

In the field of risk analysis, integration of multiple information sources is often accomplished via a weight-of-evidence (WOE) framework. ${ }^{(8,9)}$ WOE includes a variety of approaches such as listing multiple lines of evidence ${ }^{(10)}$ and integrating multiple lines of evidence into a single performance measure using indexing, ${ }^{(11)}$ scoring, ${ }^{(12)}$ or other statistical methods. $^{(8,13)}$

Scoring, which is the assignment of weights to various lines of evidence, is one of the simplest and most popular methods in the WOE toolset. The weights assigned to the individual lines of evidence are often combined to develop a numerical WOE score. ${ }^{(8,9)}$ Weights can be specified as numerical values assigned to the lines or by the proportion of the final index value that each line represents. Scoring, however, does not apply formal probabilistic techniques to quantify judgments regarding the weights. Alternatively, multicriteria decision analysis (MCDA) uses likelihoods to synthesize weights of evidence. In general, the MCDA process includes four basic steps: ${ }^{(9,14)}$ (1) formulating main and alternative objectives; (2) developing the criteria and metrics; (3) measuring performance of decision alternatives with respect to the main decision objectives using the criteria and metrics; and (4) information synthesis. ${ }^{(8)}$ In general terms, MCDA techniques aim to determine a preference order among a number of available options in a multidimensional crite- ria space based on various types of information obtained from best professional judgments, empirical measurements, or other sources. ${ }^{(14-17)}$ For each criterion, a decisionmaker must provide a score, whether in cardinal or ordinal scale, ${ }^{(18,19)}$ and the multicriteria method is then used to aggregate the individual criteria scores into an overall option preference/performance ranking (see more detailed reviews in Figueira et al..$^{(19)}$ and Moffett and Sarkar $\left.{ }^{(20)}\right)$.

Linear weighted averaging (LWA hereafter) represents one of the simplest score aggregation methods. ${ }^{(18)}$ When constructing a pest risk map composed of $j$ elements (i.e., map cells), the criteria (i.e., the independent risk components $k=1, \ldots, K$ ) are standardized to scores that are then combined by weighted averaging into a continuous metric: ${ }^{(18,21)}$

$$
R_{j}=\sum_{k=1}^{K} Z_{j k} w_{k},
$$

where $Z_{j k}$ is the normalized value of criterion $k$ for element $j$, which falls within a common numeric interval, [ $\left.Z_{\min }, Z_{\max }\right]$, and $w_{k}$ is the normalized weight for criterion $k$. Each criterion can be scored on a fixed scale, for instance [0-10], with 10 representing the most undesirable outcome (or vice versa). ${ }^{(18)}$ To score each criterion's original value range to a common fixed scale a simple linear transformation is often used. However, the rationale for doing so is often unclear. ${ }^{(22)}$ LWA also assumes a linear propagation of uncertainty from individual criteria scores to an aggregated metric, $R_{j}$. This makes the results highly sensitive to the values of the scaling coefficients and makes their derivation a critical and knowledge-demanding step of the analysis. ${ }^{(12)}$

LWA techniques have been used by the Canadian Food Inspection Agency (CFIA), USDA APHIS, and USDA Forest Service for integrated risk assessment of new invasive species. ${ }^{(23,24)}$ For example, the CFIA technique estimates two independent risk criteria, (1) the likelihood of introduction and (2) the potential impact of introduction for a new pest, and scores them into a semiquantitative scale ranging from 0 (extremely low risk) to 3 (high risk). The estimate of the potential impact includes independent estimates of four major risk criteria, including the pest's establishment and spread potential as well as its economic and environmental consequences. The aggregated risk rating is then calculated by linear weighted averaging.

The USDA Forest Service, Forest Health Technology Enterprise Team used a somewhat similar 
technique to generate national-scale risk maps for a number of nonnative forest pests. ${ }^{(24)}$ The analysis steps included acquiring spatial data to represent criteria related to the pest's introduction and establishment potential, followed by subsequent rescaling of each identified criterion to a $0-10$ scale using linear methods or according to specific thresholds selected by a risk map steering committee. Then, the factors describing the pest's introduction potential were aggregated in a single map using linear weighted averaging. Similarly, factors related to the pest's successful establishment were combined. Finally, the previous two analysis products were combined into a "susceptibility potential" product.

Several alternative algorithms have been proposed to estimate a set of weights $w_{k} \cdot{ }^{(16,19)}$ Examples include pairwise comparisons and outranking techniques, ${ }^{(25,26)}$ the analytic hierarchy process, ${ }^{(27)}$ and direct assignment. ${ }^{(28)}$ Another approach employs the multiattribute value concept ${ }^{(29)}$ to build a singledimensional utility function that represents the preferences of a decisionmaker and then uses it to evaluate the performance of multiple decision alternatives. In most cases, estimation of the weighting coefficients $w_{k}$ requires some exogenous information about their relative importance (i.e., in our case the contribution of a particular risk factor to the successful introduction of an invasive organism). However, such knowledge is often unavailable for new or anticipated (i.e., organisms that have high likelihood of introduction but have not been detected recently) invaders. As a result, determinations of weights are rarely precise and are often limited to listing the evidence or best professional judgments based on experts' anticipations of the invader's behavior. ${ }^{(9,30)}$ Several approaches have been proposed to reduce experts' biases (such as constructed ${ }^{(31)}$ or triangulatory ${ }^{(32,33)}$ ranking techniques, representing experts' beliefs as distributions ${ }^{(30)}$ and their subsequent rankings via stochastic dominance criteria, ${ }^{(30,34,35)}$ or using fuzzy rules for multicriteria aggregation ${ }^{(36-38)}$ ), but again, all of these modifications do not truly eliminate the need for prior knowledge about the individual criteria and their importance.

\section{METHODS}

\subsection{Basic Concept}

In this article we propose a new technique to synthesize individual risk component maps that does not require prior information about the criteria weights

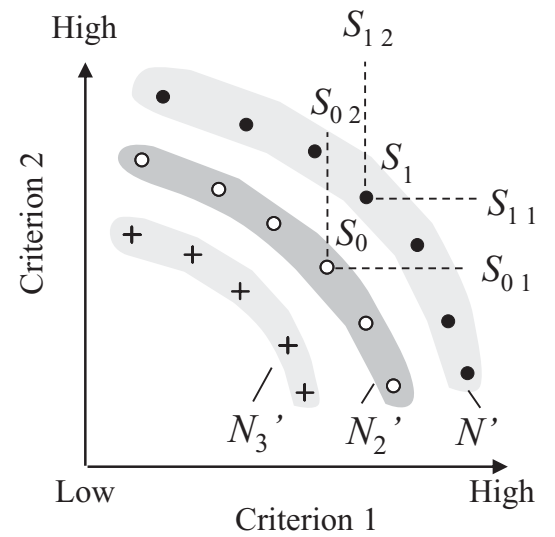

Multiattribute efficient frontiers:

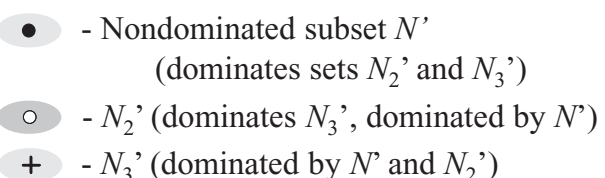

Fig. 1. The multiattribute efficient frontier concept (a twodimensional example, $K=2$ ): $N^{\prime}, N_{2}{ }^{\prime}, N_{3}{ }^{\prime}$-nested multiattribute frontiers. Point $S_{1}$ in the first multiattribute frontier $N^{\prime}$ dominates point $S_{0}$ in the second frontier $N_{2}$ ' (i.e., $S_{11} \geq S_{01}$ and $S_{12} \geq S_{02}$ in the criteria dimensions 1 and 2).

$w_{k}$ to aggregate the criteria scores into a singledimension performance metric (i.e., integrated pest risk in our case). In short, we delineate nested multiattribute efficient frontiers in dimensions of individual criteria $Z_{j k}$ and use them to aggregate the criteria scores. The method first depicts individual geographical locations $j$ as a point cloud in the criteria space $K$ and then finds the first convex multiattribute efficient frontier. In the context of a pest risk map, the points on the first multiattribute efficient frontier represent those locations (i.e., map cells) with the highest aggregated risk combinations, such that no other points exhibit combinations of risks higher than those of the locations on the frontier (Fig. 1). We assign all points on the efficient frontier an integrated risk rank of 1 . These points are then removed and a new efficient frontier is constructed with all points along this second frontier assigned a rank of 2, and so on. Essentially, the knowledge about risk criteria combinations is drawn from a partial order of elements in each risk criterion and the topology of the multiattribute criteria space.

Formally, our approach addresses the particular issue of ranking a vector of scores on an attribute where the score on each attribute is only a rank, and 
may be subject to uncertainty. This situation is fairly common when no information is available about how the attributes rank versus one another (i.e., there is no prior knowledge about $w_{k}$ ) and therefore an analyst wants to avoid using a compensatory linear averaging approach ${ }^{(18)}$ to determine the tradeoffs between the attributes or lexicographic techniques ${ }^{(39)}$ (which first focus on the performance on the most important attribute, then go to the next most important, and so on).

We then compare the performance of an aggregation technique based on the multiattribute frontier ranking (MAF hereafter) with the traditional linear weighted averaging (LWA) technique for the situation where knowledge about the criteria scores $Z_{j k}$ is uncertain. We undertake a series of sensitivity analyses to introduce uncertainties into the individual criteria values and evaluate how they affect the robustness of aggregated risk rankings to uncertainty in both techniques.

\subsection{Finding the Multiattribute Frontier}

Consider a set of $K$ risk maps, $(K>1, k=$ $1, \ldots, K)$, each representing a particular aspect of risk (i.e., a criterion) associated with an invasive organism (such as the likelihood of introduction, climatic suitability, or abundance of a susceptible host). Assuming that each risk map $k$ consists of $N$ individual locations (i.e., map cells), each location $j$ ( $j$ $\in 1, \ldots, N)$ can be represented as a point in $K$ dimensions. The points that represent these individual map locations $j$ can then be arranged as a $K$ dimensional point cloud, $\Re$, where the position of each point in the cloud is defined by the point's values for the individual risk criteria $k, k=1, \ldots, K$. If the $k$ dimensions are oriented so their highest values denote the most severe risks, then the outer convex boundary of the point cloud $\Re$ represents the combination of the highest possible risks (i.e., boundary $N^{\prime}$ in Fig. 1). Essentially, this convex boundary represents a multiattribute efficient frontier of the point cloud $\Re$ that is defined by the points for which performance with respect to one risk criterion cannot be improved without sacrificing performance with respect to at least one other criterion, a condition also known as Pareto optimality. ${ }^{(40)}$ For a set of $N$ points in a $K$-dimensional criteria space, the multiattribute efficient frontier is outlined by the subset of the total population, $N^{\prime}$, that is nondominated by the rest of the population (i.e., $N-N^{\prime}$ ). The concept of a multi- attribute efficient frontier can be further illustrated using a simple two-criteria case (i.e., $K=2$ ) (Fig. 1). For example, the points in the first multiattribute frontier $\left(N^{\prime}\right)$ in Fig. 1 are nondominant to each other but dominate the points in frontiers $N_{2}{ }^{\prime}$ and $N_{3}{ }^{\prime}$. In a $K$-dimensional criteria space, a point $S_{1}$ dominates another point $S_{0}$ when:

$S_{1 \mathrm{k}} \geq S_{0 \mathrm{k}} \forall k=1, \ldots, K$ and $S_{1 \mathrm{k}}>S_{0 \mathrm{k}}$ for some $k$.

The approach shares some conceptual details with data envelopment analysis (DEA). Although DEA is not a multicriteria analysis technique per se, it uses the principle of delineating a multiattribute efficient frontier when ordering a set of decisionmaking choices. ${ }^{(41-44)}$ DEA focuses mostly on the performance evaluation of managerial choices in production economics that use a common set of resources and produce a common set of outputs. ${ }^{(41)}$ In particular, our technique has some similarities with the "tiered" version of DEA (TDEA), ${ }^{(43)}$ which evaluates nested multiattribute efficient frontiers to order decision-making alternatives in dimensions of multiple production inputs and outputs.

Finding the multiattribute frontier represents a special case of the maximum vector problem that allocates the nondominated subset of a multidimensional set of vectors. ${ }^{(45)}$ A similar procedure is alternatively labeled a "skyline" operator. ${ }^{(46,47)}$ The concept has also been used in many theoretical applications such as the contour problem, ${ }^{(48)}$ multiobjective optimization, ${ }^{(45,49)}$ and computing the convex hull of a multivariate data set. ${ }^{(50,51)}$

It is evident from Fig. 1 and Equation (2) that the delineation of nested frontiers depends on a partial order of individual data elements in the $K$ dimensional criteria space. If any of the $K$ criteria have skewed or clustered distributions, this may greatly reduce the capacity to delineate the frontier, so normalization is effectively necessary. To address this aspect, we follow the ranking standardization of the score value along each criteria dimension $k$ described by Godfrey et al. ${ }^{(52)}$ to satisfy the conditions of sparseness and uniformity. The standardization ensures that individual points in the $K$-dimensional cloud (i.e., map locations $j$ ) will have distinct values along any dimension $k$; preferably, the distribution of point values along a given dimension will be as close to uniform as possible. ${ }^{(52)}$ For each criterion dimension $k$, we assign an ordinal rank $r_{j k}$ to each point, $0, \ldots, \phi_{\mathrm{k}}-1$, where $\phi_{k}$ is the number of distinct point values on dimension $k$. The lowest value on $k$ is 


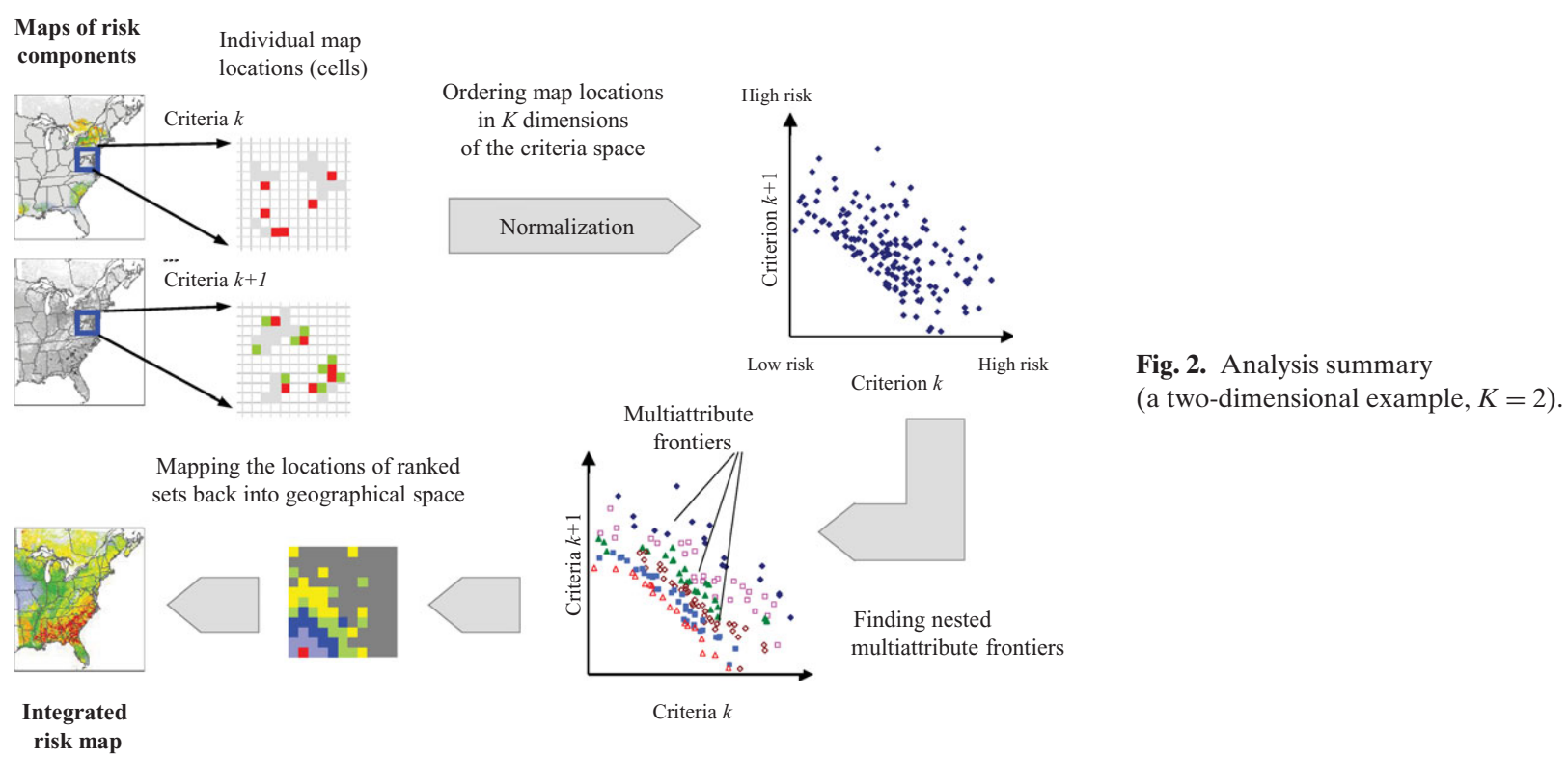

assigned a rank of 0 and so forth. The normalized point values are then calculated as $\left(r_{j k}+1\right) /\left(\phi_{k}+\right.$ $1)$. This transformation preserves the partial order of elements and dominance relations in each criterion dimension.

\subsection{Building Integrated Risk Maps}

Prior to ranking, we assigned unique identifiers to each map unit and then converted units to the points in $K$-dimensional criteria space (Fig. 2). Next, we used Goldberg's ${ }^{(53)}$ ranking algorithm to delineate multiattribute frontiers in the criteria space. The method first finds $N^{\prime}$, the initial set of nondominated points (i.e., the first multiattribute frontier) from the multicriteria point cloud $\Re$, assigns them rank 1 , and then removes these elements from $\Re$ temporarily. Next, a second nondominated subset, $N_{2}{ }^{\prime}$, is determined from the rest of $\Re$, assigned a rank of 2 , and temporarily removed, and so forth until every point in $\Re$ has been assigned a frontier rank. After the ranking is complete, we used the points' identifiers to map the frontier ranks in geographical space (Fig. 2).

In order to compare different scenario realizations, we inverted and rescaled ordinal ranks to a [0;1] range so the values close to 1 denote the first frontier (i.e., the most severe combinations of risks) and the ranks of the lowest frontiers were close to 0 . Conceptually, the analysis is similar to the map aggregation procedure described in Yemshanov et al. ${ }^{(54)}$

\subsection{Species of Interest}

We demonstrate the approach with a risk map for the oak splendor beetle, Agrilus biguttatus, a significant pest of oak forests in Europe, Russian Asia, northern Africa, and the Middle East. ${ }^{(55-57)}$ It is believed that $A$. biguttatus is one of the main causes of oak decline in Europe ${ }^{(58)}$ and is expected to cause significant impact to natural and urban forest environments if introduced into North America. ${ }^{(59)}$ A. biguttatus is most likely to encounter a suitable climate for establishment in the continental United States and southern parts of Canada and cause major damage to oak species (Quercus spp.) as its primary hosts. ${ }^{(55-57,59)}$

However, there is little knowledge available regarding the pest's behavior in North America ${ }^{(60)}$ because the bulk of the quantitative information about $A$. biguttatus comes from other regions overseas where the pest is already established. Hence, instead of using a dynamic model of pest establishment (which would require providing many yet unknown parameters about the pest's behavior in North America) we have selected a simple, static model that is limited to the available knowledge about the pest and predicts the most likely factors of successful establishment of $A$. biguttatus populations. Based on the scarce available information, a panel of scientists (convened by the USDA Forest Service, Forest Health Technology Enterprise Team for this purpose) identified three major drivers of successful 
invasion: (1) the potential for introduction at North American ports of entry receiving associated commodities from locations in the insect's current range, and at urban areas and distribution centers linked to these ports; (2) the abundance of host (oak trees); and (3) the potential degree of drought stress to host trees during the late spring-early summer season. For our study, we created three maps, each representing one of these risk criteria for A. biguttatus. The maps (see online Appendix 1) encompass the entire oak distribution range in the United States and Canada. Among the three major factors of invasion, host distribution is the only aspect particular to $A$. biguttatus ecology (as suggested by limited knowledge about the pest $\left.{ }^{(59)}\right)$. The other two criteria (i.e., drought stress and the potential for human-mediated introductions) have been well recognized as common contributors to alien forest insect establishments in North America. ${ }^{(2,4)}$

The Canadian portion of the drought index map was estimated as the standard deviations of the Canadian climate moisture index $(\mathrm{CMI})^{(61)}$ from its 30-year average value. For the United States, we determined drought status according to standard deviations of a similar moisture index ${ }^{(62)}$ calculated specifically for the period of late spring-early summer. The U.S. portion of the drought index map was based on a weighted average of the drought deviations for the last 10 years and last 100 years in the proportions 4:1 (to emphasize the importance of more recent droughts). The Canadian portion of the drought map was interpolated from $10-\mathrm{km}$ resolution data, while the U.S. portion was based on 4-km spatial resolution data. These differences in the original data and map interpolation methods explain the differing textural appearances of the U.S. and Canadian portions of the map (Appendix 1A).

The host abundance map (Appendix 1B) was derived from the USDA Forest Service, Forest Inventory and Analysis (FIA) database ${ }^{(63)}$ for the United States and the National Forest Inventory ${ }^{(64)}$ for Canada. The map depicts the distribution of oak species abundance (in basal area units) across North America inclusive of urban areas. We also used previously published oak species range maps ${ }^{(65)}$ to demarcate the geographic extent of oak species distribution in North America.

The U.S. portion of the pest's introduction potential map (Appendix 1C) was developed from (1) the locations of principal ports of entry that receive imports from countries where $A$. biguttatus is known to be present, and from commodity categories that have been historically associated with Buprestidae interceptions; (2) major urban markets, to which these associated commodities are primarily transferred; and (3) locations of distribution centers that handle imported goods. In a geographic information system (GIS), we applied an inverse cost distance function $^{(66)}$ from the ports, major urban markets, and distribution centers to project the pest's introduction potential in other (i.e., rural) locations. Unsurprisingly, the map shows the highest risks of introduction for major-market urban areas and in the vicinity of high-volume marine ports (Appendix 1C). The Canadian portion of the map used similar information except the data on distribution centers were substituted with urban population density at the level of Census subdivisions within the municipal limits. We used 2006 StatsCan population density data ${ }^{(67)}$ and the Canadian road geo-database ${ }^{(68)}$ to map the location of major urban markets.

\subsection{MAF and LWA Risk Rankings in the Presence of Uncertainty}

We applied the concept of robustness to uncertainty ${ }^{(69)}$ to compare the performance of the MAFbased and the MCWA aggregation techniques in the presence of uncertainties in the criteria values. For both methods, we used the three previously described risk criteria data sets (i.e., drought stress, host distribution, and introduction potential), which we standardized to a range between 0 and 1 . Because the MAF aggregation does not use criteria weights $w_{k}$, we assumed equal weights $\left(w_{k}=1\right)$ in the LWA scenario to make a valid comparison.

To perform the comparison, we used an approach similar to that presented in Yemshanov et al. ${ }^{(70)}$ Briefly, our analytical framework for characterizing robustness to uncertainty is based on the principles of info-gap decision theory. An info-gap decision model includes three basic components. The "process model" describes what is known about the phenomenon of interest and is deemed to be the best (though uncertain) representation of its behavior; for this analysis, our "process model" consisted of the input risk criteria, $Z_{j k}$, and the risk aggregation model (i.e., the MAF or LWA rankings). The "uncertainty model" describes the unknown variation in the structure, parameters, and assumptions of the process model. The process model is also used to estimate a "performance requirement" 
metric that describes the outcome the decisionmaker wants to achieve (for example, a certain minimum risk threshold).

Our analysis started from a "nominal" scenario utilizing the current estimates for our three risk criteria, $\bar{Z}_{j k}$ (i.e., the criteria maps in Appendix 1). Our corresponding model for uncertainty describes what is unknown about the criteria values in the risk mapping model, and was defined such that the individual criteria values $Z_{j k}$ could deviate from their nominal values by an unknown fraction. Since we had no prior knowledge about the actual degree of uncertainty of the $Z_{j k}$ values, we adopted a simple uniformbound model, $U(h)$, where each criterion value deviates from its nominal value by a proportion $h$ or less, but the value of $h$ is not known:

$$
\begin{aligned}
U(h)= & \left\{Z_{j k}: Z_{j k} \in[0 ; 1],\left|Z_{j k}-\bar{Z}_{j k}\right| \leq h \bar{Z}_{j k},\right. \\
& \text { for all } j \text { and } k\}, h \geq 0 .
\end{aligned}
$$

Note that the uncertain criteria values $Z_{j k}$ are not allowed to take negative values.

The risk rank of a map location is defined so that larger values are more critical for the decisionmaker. Here, we assume the responsible decisionmaker will likely take action only when serious risks are confidently anticipated. In essence, this cautious decisionmaking strategy reflects the attitude that large irreversible actions regarding the regulation and control of new invasive pests should be initiated only when the danger of inaction is clear and present. Note that this strategy should be distinguished from a precautionary strategy under which action is taken when severe adverse outcomes are plausible. Given that knowledge about new or anticipated invasive pests is usually poor, we assume a decisionmaker would follow a cautious decision-making strategy when using the risk map as a decision support aid.

Let $R_{j}(Z)$ be the risk value at map location $j$, which depends on highly uncertain values of $Z_{j k}$, denoted collectively by $Z$. An irreversible high-cost action will be taken at location $j$ only if the risk value $R_{j}(Z)$ is confidently assessed to be high. Let $\bar{Z}$ be the estimated value of the uncertain quantities $Z$. Thus, the estimated risk at location $j$ is $R_{j}(\bar{Z})$. If this estimated risk is acceptably low, then no action is indicated according to the cautious decisionmaking strategy. However, if the estimated risk is high, we ask: Are we confident that this estimate is correct? What is the highest level of uncertainty at which the risk value is still large enough to justify a high-consequence action? The answer to this ques- tion is the robustness function, which is defined as the largest horizon of uncertainty, $\hat{h}$, at which the risk value is still high enough to justify an irreversible action (such as control, regulation, or surveillance). Let $R_{j \min }$ denote the lowest level of risk that, if confidently assessed, indicate the need for a regulatory, surveillance, or mitigation effort. The robustness of the risk map at location $j$ then can be defined as:

$$
\hat{h}_{j}\left(R_{j \min }\right)=\max \left\{h:\left(\min _{Z \in U(h)} R_{j}(Z)\right) \geq R_{j \min }\right\} \text {. }
$$

A large value of $\hat{h_{j}}\left(R_{j \min }\right)$ means a risk value at least as high as $R_{j \min }$ will occur for any realization of the uncertain quantities $Z$ up to a large horizon of uncertainty, $\hat{h}$. In practical terms, a large robustness value means that a decisionmaker can confidently assert that the risk at location $j$ is substantial, which indicates that action should be taken. The inner minimum in Equation $(4), \mu_{j}(h)$, is the inverse of the robustness $\hat{h}_{j}\left[R_{j \mathrm{~min}}\right]{ }^{(69)}$ or in other words, is the value of $R_{j \min }$ at which the robustness, $\hat{h}_{j}$ $\left[R_{j \min }\right]$, equals $h$. This inner minimum was found iteratively via stochastic simulations. Because of our lack of knowledge regarding $\hat{\mathrm{h}}$, we searched the model of uncertainty $U(h)$ for a set of nested intervals $h$ ( $h \in[0 ; 0.7])$ in order to obtain the corresponding criteria values $Z_{j k}$ over $M$ independent rankings, $m=1, \ldots, M$ :

$$
\left[\begin{array}{c}
Z_{j k_{m}} \\
Z_{j k_{m}} \in U(h)
\end{array}\right]_{m=1, \ldots, M} \stackrel{M}{\Rightarrow} \min _{m} R_{j}\left(Z_{j k_{m}}\right)
$$

Notably, the value of $\min R_{j}\left(Z_{j k m}\right)$ decreases when uncertainty, $h$, in the criteria values increases. This means that the robustness, $\hat{h}_{j}\left[R_{j}\right.$ min $]$, decreases as $R_{j \min }$ increases, reflecting a lack of confidence in correctly identifying high-risk locations.

We used the shape of the robustness function $\hat{h}_{j}\left[R_{j} \min \right]$ to compare the performance of the MAF and LWA methods in the presence of uncertainties. We calculated the robustness estimates for all geographical locations in our risk map area (i.e., the contiguous United States and Canada). The geospatial aspects of the technique are similar to the analysis described in Yemshanov et al. ${ }^{(70)}$ In this case, for each map cell $j(j=1, \ldots, J)$, two robustness curves (as depicted in Equation (5)) were generated separately for the MAF and LWA techniques, $\hat{h}_{j}\left[R_{j} \text { min }\right]_{\mathrm{MAF}}$ and $\hat{h}_{j}\left[R_{j} \text { min }\right]_{\text {LWA }}$. (Both curves have the same units, permitting straightforward comparison.) Finally, we 
computed a map of Euclidean distances, $D_{j}$, between the MAF and LWA robustness curves. These are computed with the inverses of the robustness curves, $\mu_{j}(h)$. We evaluated the distance between the MAF and LWA robustness curves in terms of the distance between $R_{j}$ min values at horizons of uncertainty, $h_{i}=$ $0,0.1,0.3,0.5$, and 0.7 :

$$
D_{j}=\sqrt{\sum_{i=1}^{5}\left[\mu_{j}\left(h_{i}\right)_{\text {Pareto }}-\mu_{j}\left(h_{i}\right)_{\mathrm{MCWA}}\right]^{2}} .
$$

Essentially, the map of $D_{j}$ delineates the locations where the MAF and LWA robustness curves have similar (or apparently different) behavior.

\section{RESULTS}

\subsection{Integrated Risk Ranks in the Nominal Scenario}

The integrated risk maps generated with the MAF and LWA methods in the nominal scenario (Fig. 3) largely agree in terms of the relative geographic distribution of their highest and lowest risk areas, as reflected by high Spearman rank correlation $\left(r_{s}=0.89\right)$ values between them for the entire map area. For example, in both maps the highest risks have been assigned to large urban centers and regions under severe drought stress in the southeastern United States. Notably for the MAF-based map (Fig. 3a), the highest risk ranking class includes all locations (i.e., map cells) where at least one risk criterion is at its maximum value. As a result, given a similar number of output risk classes, the MAFbased aggregation always allocates a larger number of map cells to the highest risk class than the LWA technique (Fig. 3b). This aspect is illustrated with a schematic comparison of the MAF-based ranks and same-width LWA rankings (Fig. 4); note that some points assigned to the highest multiattribute frontier (rank 1) are assigned a lower risk rank in the LWA ranking (i.e., rank 2). Perhaps more significantly, the LWA aggregation simply assigns more points to medium-risk ranks than the MAF aggregation as a result of a compensatory effect, where high risk in one criterion is compensated by low risk in another. Because the LWA integrated risks are based on linear averaging, the LWA map shows more gradual transitions between high- and low-risk areas, and fewer maxima (Fig. 4).

The correspondence between the MAF and LWA risk ranks has been summarized for the entire risk map area and for four broad geographic regions (Table 1): the northern United States, the southern United States, the western United States, and Canada (see Fig. 5c for a map of these regions). In each region, the LWA-generated risk values are distributed closer to their overall averages, such that fewer risk values are found in the extreme risk classes. The MAF ranking consistently assigns 0.08-0.12 higher risk values compared to the LWA. Again, this is evidence of the compensatory effect in the LWA method. ${ }^{(18)}$

\subsection{Robustness of Integrated Risk Ranks to Uncertainty}

The robustness curves, $\hat{h}_{j}\left[R_{j} \min \right]$, for both the MAF and LWA aggregations have also been summarized (Fig. 5a) at the level of our four broad geographic regions (northern United States, southern United States, western United States, and Canada). The MAF-based risk ranks exhibit higher robustness to uncertainties when the aspirations regarding the outcomes are demanding (i.e., in cases when decisionmakers, as risk map users, are particularly concerned with identifying the highest risk areas, and thus set higher $R_{j \min }$ threshold values). The LWA rankings show better robustness to uncertainty when the required quality of the outcome is low (i.e., when low values of $R_{j \min }$ are acceptable, Fig. 5a). This difference can be explained by the discrete nature of the MAF aggregation. Because the delineation of the multiattribute frontiers is based in our case on a partial order of points in each criteria set, small errors in criteria values are unlikely to change the rank order, and hence do not have much effect on the relative positions of the multiattribute frontiers. Alternatively, the LWA aggregation method uses linear averaging, and therefore any errors in the individual risk criteria values propagate to the integrated risk estimates and thus decrease the robustness to uncertainty. However, when errors in the original criteria values become large, they may considerably alter the order of elements in a multidimensional set and the subsequent delineation of the multiattribute frontiers. As a result, when the risk rankings do not have to be precise (i.e., when low $R_{j \min }$ is acceptable), the MAF loses its competitive advantage over LWA. This explains the preference reversal in the robustness functions for all regions except the southern United States (Fig. 5a). In summary, the MAF-based aggregation may be a more reliable choice when a decisionmaker's aspirations are high. 
(a) MAF-based aggregation

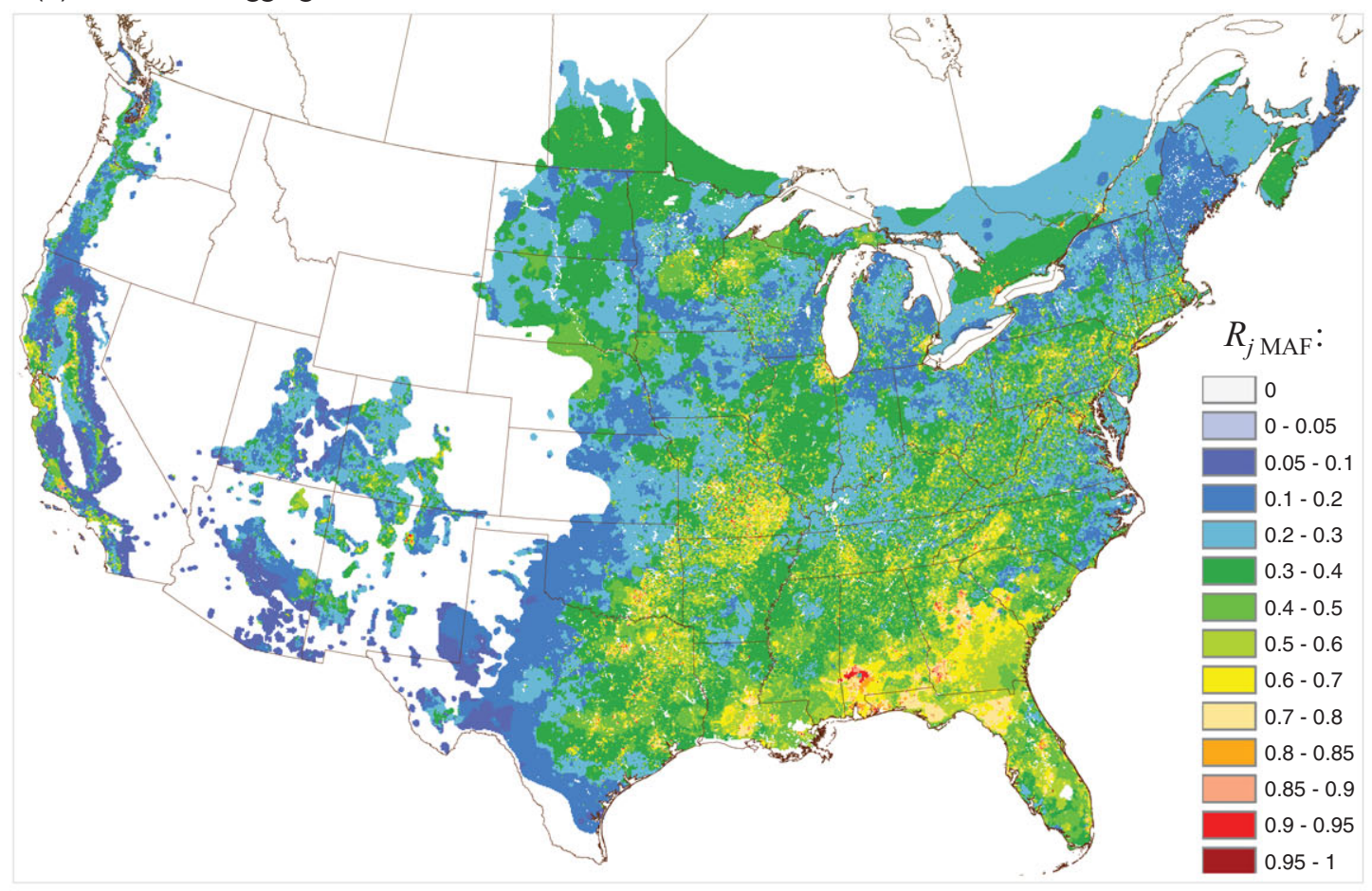

(b) LWA aggregation

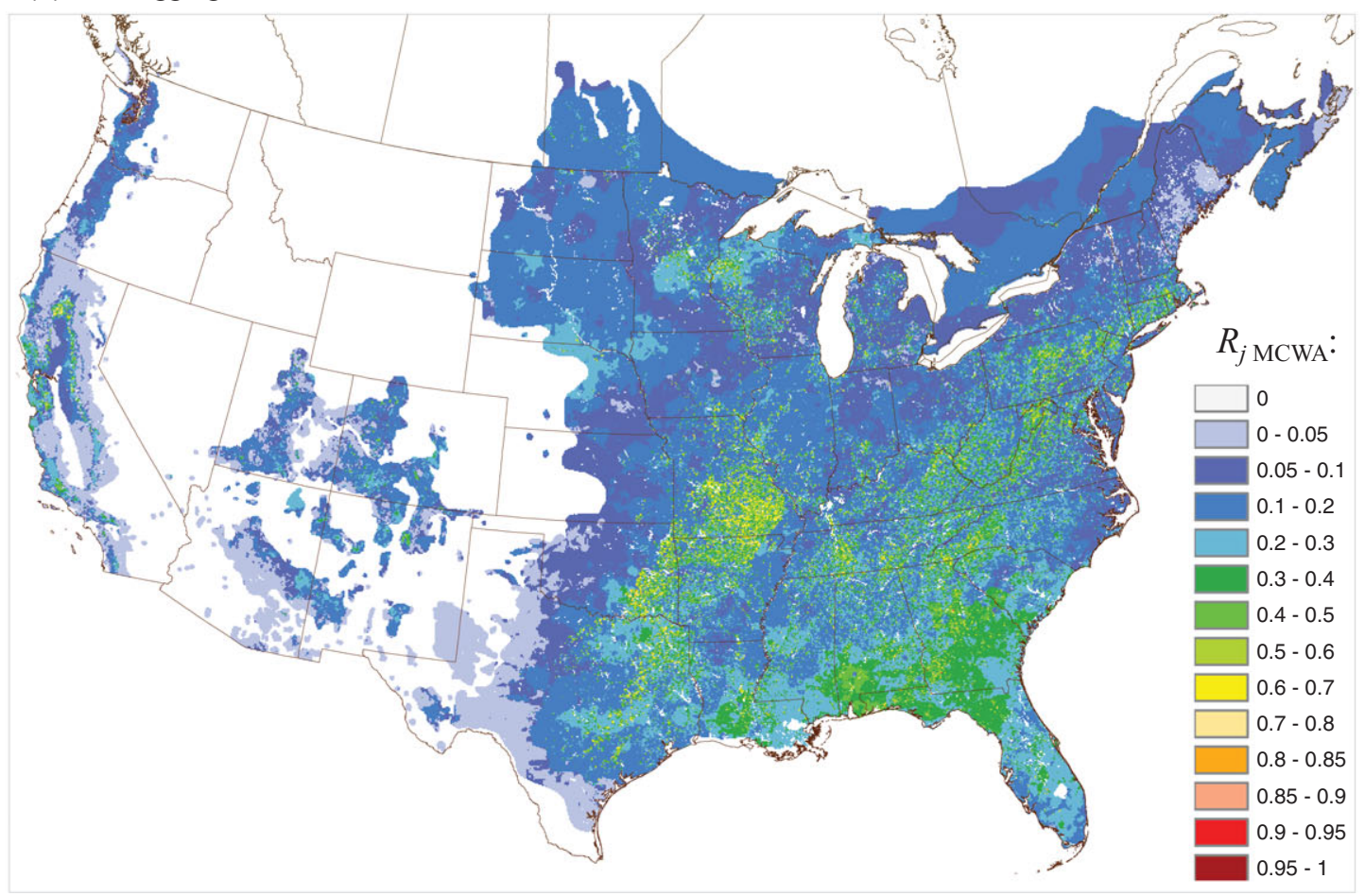

Fig. 3. Aggregated risks in the nominal scenario: (a) MAF-based ranking; (b) LWA technique. 


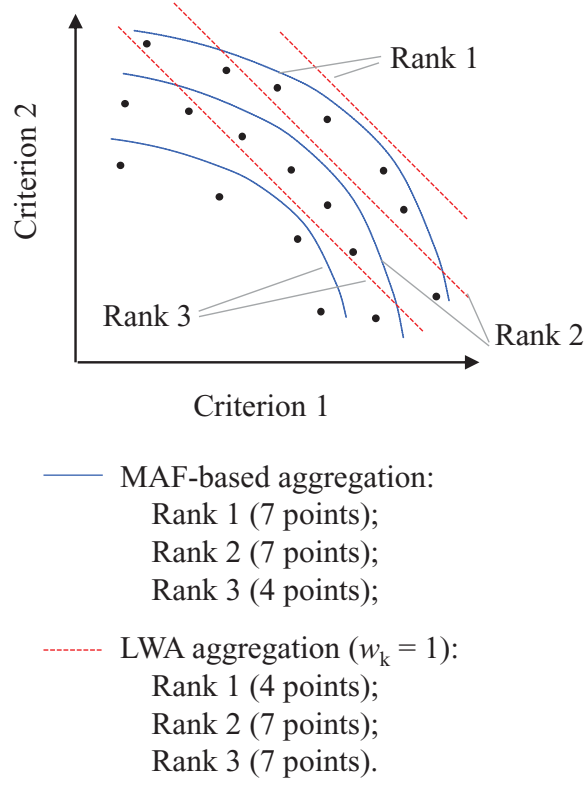

Fig. 4. Conceptual example of MAF-based risk ranks and their equivalents delineated by the LWA technique.

We also recalculated the robustness functions for high-risk regions only (i.e., where the $R_{j}$ values exceeded 0.67 in at least one of classifications, Fig. 5b). Here, the MAF-based aggregation shows considerably higher robustness to uncertainty for all scenarios, especially in the western United States and Canada. This again can be explained by the discrete nature of the frontier-based ranking technique. Because the delineation of frontiers starts with the highest risk values and progresses through incrementally lower risk values, any errors in delineating a given risk rank are transferred to the delineation of the subsequent rank. However, since the highest risk ranks are delineated early in this process, they are less likely to be affected by such errors. This contrasts with the continuous gradient of risk values generated by LWA and the resulting linear propagation of uncertainties from the input criteria to the aggregated risk estimates.

In both Figs. 5a and 5b, the regional robustness curves for the MAF aggregation exhibit steeper declines than their LWA counterparts. This implies that the MAF-based aggregation is likely to be more responsive to improved knowledge (i.e., reduced uncertainty) regarding the individual risk criteria. In contrast, the LWA robustness curves are relatively flat and do not change very much in response to the level of uncertainty (or alternatively to improved knowledge).
Table I. Correspondence Between the MAF-Based and LWA Integrated Risk Rankings

\begin{tabular}{|c|c|c|c|c|c|}
\hline \multirow{2}{*}{$\begin{array}{l}\text { LWA } \\
\text { Risk } \\
\text { Class }\end{array}$} & \multicolumn{5}{|c|}{ MAF-Based Risk Class } \\
\hline & $0-0.2$ & $0.2-0.4$ & $0.4-0.6$ & $0.6-0.8$ & $0.8-1$ \\
\hline \multicolumn{6}{|c|}{ All Regions (United States and Canada) } \\
\hline $0-0.2$ & $28.0^{*}$ & $69.9^{* *}$ & 1.6 & 0.5 & \\
\hline $0.2-0.4$ & & 12.9 & 75.3 & 11.8 & 0.1 \\
\hline $0.4-0.6$ & & & 38.0 & 60.7 & 1.3 \\
\hline $0.6-0.8$ & & & & 86.0 & 14.0 \\
\hline $0.8-1$ & & & & & 100.0 \\
\hline \multicolumn{6}{|c|}{ Northern United States } \\
\hline $0-0.2$ & 24.0 & 73.8 & 1.7 & 0.5 & \\
\hline $0.2-0.4$ & & 21.5 & 76.2 & 2.3 & 0.05 \\
\hline $0.4-0.6$ & & & 47.1 & 52.7 & 0.2 \\
\hline $0.6-0.8$ & & & & 84.4 & 15.6 \\
\hline $0.8-1$ & & & & & *** \\
\hline \multicolumn{6}{|c|}{ Southern United States } \\
\hline $0-0.2$ & 29.3 & 68.1 & 1.9 & 0.6 & \\
\hline $0.2-0.4$ & & 10.3 & 74.6 & 15.0 & 0.1 \\
\hline $0.4-0.6$ & & & 33.2 & 65.1 & 1.7 \\
\hline $0.6-0.8$ & & & & 87.5 & 12.5 \\
\hline $0.8-1$ & & & & & 100.0 \\
\hline \multicolumn{6}{|c|}{ Western United States } \\
\hline $0-0.2$ & 57.1 & 41.2 & 1.4 & 0.3 & \\
\hline $0.2-0.4$ & & 6.3 & 83.7 & 9.8 & 0.2 \\
\hline $0.4-0.6$ & & & 33.4 & 62.3 & 4.3 \\
\hline $0.6-0.8$ & & & & 89.1 & 10.9 \\
\hline $0.8-1$ & & & & & *** \\
\hline \multicolumn{6}{|l|}{ Canada } \\
\hline $0-0.2$ & 6.0 & 92.5 & 0.9 & 0.6 & \\
\hline $0.2-0.4$ & & 27.1 & 48.3 & 24.0 & 0.6 \\
\hline $0.4-0.6$ & & & 42.4 & 10.8 & 46.8 \\
\hline $0.6-0.8$ & & & & 1.4 & 98.6 \\
\hline $0.8-1$ & & & & & \\
\hline
\end{tabular}

Note: The rows show the percentage of map cell values in each of six MAF-based risk classes that fall within a given LWA risk class. ${ }^{*}$ Shaded cells show diagonal elements of a correspondence table (i.e., where both LWA and MAF-based rankings fall into the same risk class).

${ }^{* *}$ Row maximums are marked in bold.

${ }^{* * *}$ The LWA aggregation did not show risk classes above 0.8 for these particular regions.

A map of $D_{j}$, the Euclidean distance between the values of the two sets of robustness curves for each location (map cell) $j$, highlights geographic areas where the MAF-based and LWA total robustness curves have similar (or apparently different) behavior (online Appendix 2). In general, the highest differences were observed for major urban metropolises in Canada and the United States, as well as a portion of the southeastern United States (i.e., 
(a) All map cells
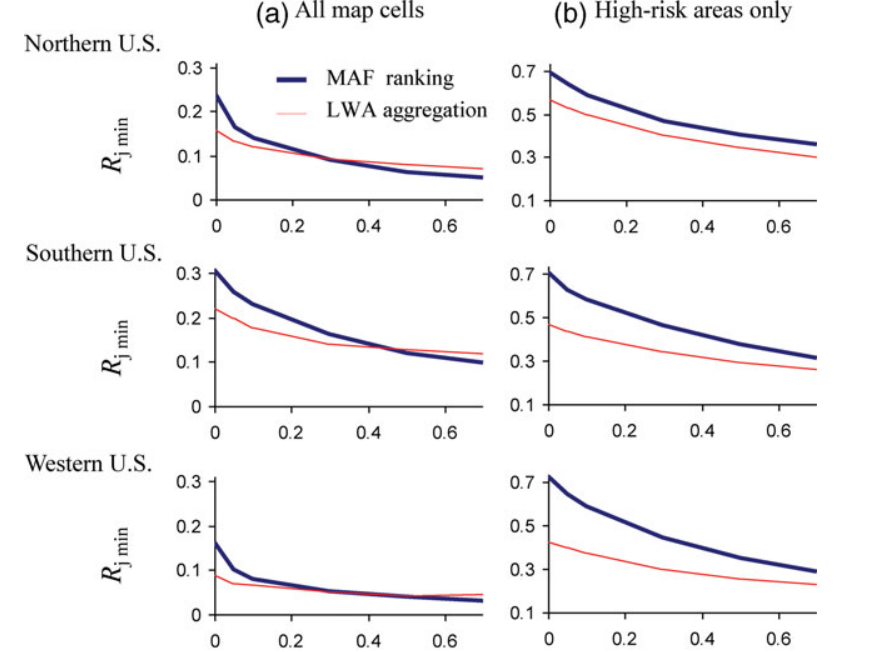

Canada
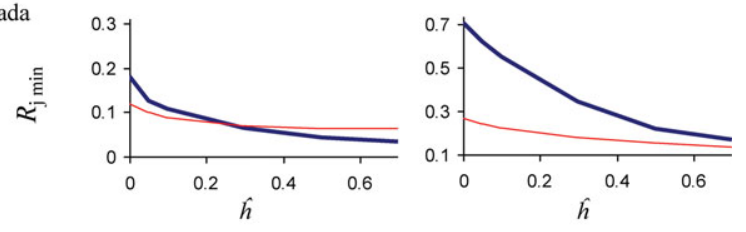

(c) Geographic regions:

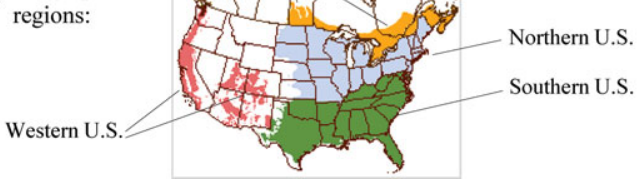

(b) High-risk areas only
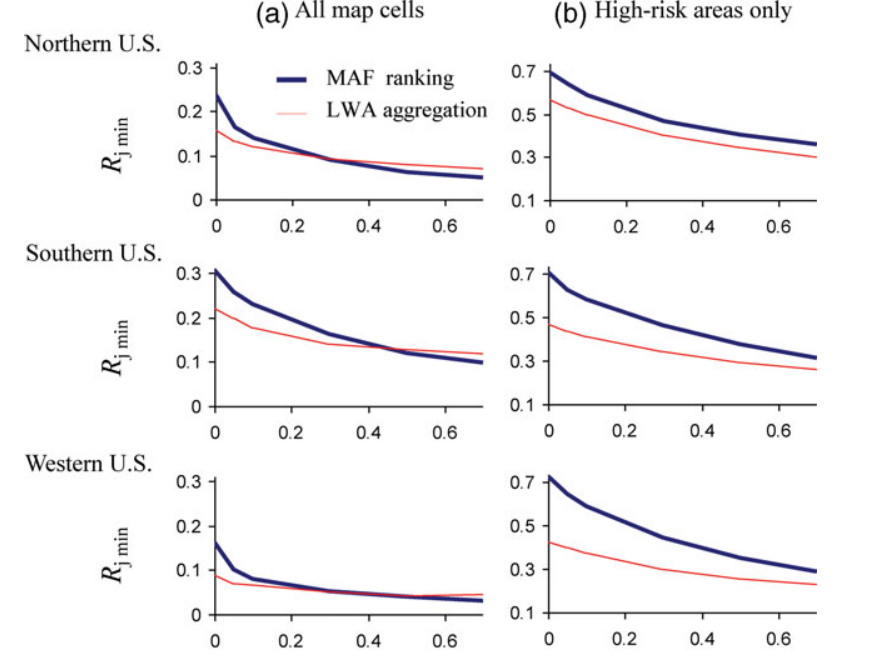

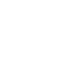


vague terms (such as "considerable" or "moderate"). In some respects, this cautious approach seems justified: although experts can generally perceive the meaningful trends in a set of risk criteria, they are rarely able to determine the precise threshold values in these criteria where invasion "success" becomes highly probable. Notably, the MAF-based approach skirts this issue of thresholds, and instead exploits the fact that each criterion in a $K$-dimensional set can be ordered along a "high-low" relative risk gradient, making it straightforward to delineate nested multiattribute frontiers in the $K$-dimensional criteria space and thus derive a full suite of integrated risk ranks (even though the trend in each risk criterion is only known vaguely).

This study used a simple, static pest invasion model to illustrate the MAF technique. Clearly, an application of a dynamic invasion model could provide valuable insights about nonlinear relationships between the drivers of the spread and successful establishment of an invasive organism. However, for many anticipated invaders (i.e., pests for which populations have yet to be detected in the region of interest), knowledge about these nonlinear relationships is nonexistent. (This information is usually collected from field observations of the organism's behavior in other regions where the species is known to be established). In this situation, a set of static proxies of the pest's establishment potential were the only data available and hence dictated our choice of a relatively simple model type. In general, it would be advisable for the analytical team to include specialists who are skilled at working through the underlying modeling methods (e.g., the methods for constructing the risk criteria), especially to be alert to emerging knowledge that could alter the risk map configurations.

\subsection{Methodological Aspects and Future Work}

The MAF and LWA techniques use fundamentally different approaches to synthesizing information about individual risk criteria. The multiattribute frontier ranking essentially "peels" convex hypersurfaces off a multicriteria point cloud, starting from the outermost layer. Alternatively, the LWA approach "slices" a multidimensional cloud into hyperplanes based on a set of criteria weights $w_{k}$ (as illustrated in Fig. 4). As a consequence, the two techniques typically yield different numbers of elements at the same level of risk.

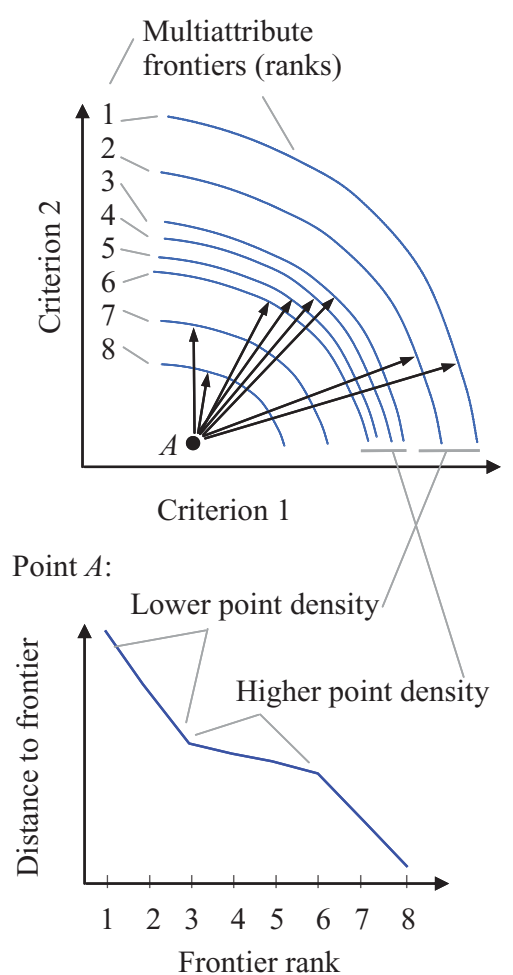

Fig. 6. Distance to multiattribute frontier as a function of the frontier's rank.

The position of the frontiers in the MAF-based approach can also be influenced by local variations of the point density across the criterion space. Because each multiattribute frontier is essentially a pointdeep $K$-dimensional surface, more frontiers can be delineated in regions of the criteria space with higher point density and vice versa. While recognizing the importance of this issue, we believe that this aspect can be quite useful to explore the structure of a multiattribute point cloud and test the significance of individual points (i.e., geographic map units in our pest risk mapping case). Local variations of point density can be identified using techniques previously developed in tiered data envelopment analysis (TDEA). ${ }^{(4)}$ For example, one could estimate the Euclidean distance from a given point to each delineated frontier in the criteria space and represent it as a function of the frontier's rank (Fig. 6). Rapid decrease of the distance to the frontier would outline regions with relatively low point density, while small declines in distance relative to rank would mark higher density regions (where the points' score values are similar). Regions of relatively low and high point density could then be mapped in a geographical space as an indication of where, geographically, 
the greatest gains in ranking precision may be possible. In addition, the position of the first multiattribute frontier that defines the worst combinations of risks for a pest of interest could be used as a "reference" when comparing risk rankings of different invasive organisms. In this case, each point below the frontier would be assessed in terms of its distance from the first frontier. Alternatively, one could estimate the probability of each point belonging to one of the first $n$ frontiers that the analyst perceives to be critical.

The precision of the MAF ranking method may be directly improved by adopting other techniques from TDEA; for example, it is possible to rank the points within a single frontier. ${ }^{(43)}$ Briefly, the contribution of each individual point to the shape of its frontier is evaluated by temporarily removing the point from the analysis and repeating the ranking. The points that significantly distort the shape of the frontier on which they were previously located (or change the frontier's rank) can be considered as more important and vice versa. Technically, testing the importance of $N$ points would require undertaking $N+1$ independent rankings. For very large $N$, such a technique would require considerable computing resources, although the procedure is highly scalable and could be easily parallelized.

The total number of integrated risk ranks that can be generated by a MAF-based technique also depends on the dimensionality of the criteria space $(K)$. Higher dimensional criteria space usually leads to fewer ranks. This makes the method suitable only for relatively low-dimensional cases where $K<15$ (note that this number of criteria dimensions is sufficient for a vast majority of ecological and pest risk mapping applications). For higher dimensional cases, the precision of the ranking can be improved by applying an algorithm similar to the one implemented in the "random forest" classification technique. ${ }^{(71)}$ The technique performs multiple rankings of subsets of the point cloud $\Re$ by withholding randomly a certain portion of the points from the analysis and generating a collection of integrated MAF rankings, each characterizing a partially overlapping subset of the original data set $\Re$. The final ranking is then calculated as the unweighted plurality of the subset ranks. According to the law of large numbers, the error rates monotonically decrease to a limit and there should be no overfitting as the number of individual subset rankings increases. ${ }^{(71)}$

Compared to the other multicriteria aggregation methods, finding a multiattribute frontier leads to a finite solution via exhaustive tests of all points for nondominance. In general terms, the method can be seen as an alternative to other techniques that aggregate multicriteria scores, with the advantage that is does not require making prior assumptions about the criteria weights. Yet, finding the multiattribute frontiers in large data sets, even without the potential refinements discussed above, represents a substantial computational effort. The most basic algorithm $^{(46)}$ requires pairwise comparison for all data points in a multicriteria cloud, with computational complexity of order $K N^{2}$. At this point, computing time represents the most significant impediment to practical application of the MAF-based technique to large data sets. Several proposed algorithms ${ }^{(46,72-75)}$ aim to reduce the computing time for large $N$. Improving the run-time efficiency of the ranking procedure and adding the aforementioned bootstrapping and advanced ranking options will be a focus of our future work.

Notably, the MAF-based technique can be further adapted to work with incomplete or imperfect data. Pest management professionals need to recognize that pest outbreaks could occur in areas classified as "low-risk" due to the imperfect input information upon which the risk maps are based. However, the impact of variability (i.e., uncertainty) associated with imprecise or potentially missing information about the pest can be assessed with a multistaged approach. First, the variability can be represented using stochastic invasion models (or sensitivity analyses) to generate multiple (but plausible) parameter values under a range of alternative model assumptions and, subsequently, to generate distributions of criteria maps instead of a single set of baseline criteria values (as depicted in Appendix 1). In the next stage, individual realizations of the risk criteria sets generated with the stochastic invasion model (or sensitivity analyses) are ranked with the MAF technique. At this point, each geographic location in the map would be characterized by a distribution of plausible risk rank values instead of a single baseline estimate. Then, the distributions of risk ranks can be compared among multiple geographic locations and aggregated into a single-dimensional risk rank using stochastic ordering techniques (such as methods based on stochastic dominance ${ }^{(76,77)}$ ) or techniques based on the mean-variance frontier concept. ${ }^{(77)} \mathrm{Im}$ portantly, the application of stochastic ordering techniques would not only incorporate the uncertainty in the underlying risk rank estimates, but would also provide a way to incorporate decision-making 
preferences with respect to this uncertainty (so the final risk ranks could accommodate specific decisionmaking behavior, such as risk aversion ${ }^{(76,77)}$ ).

\section{CONCLUSIONS}

Key policy and regulatory decisions regarding new invasive species often rely on uncertain foundations and scarce knowledge. Public concern and calls to proceed with response activities frequently come before much scientific information about a new invasive organism can be gathered, thus making a reliance on expert opinion, in the face of ignorance, an inevitable part of the policy-making process. Often, there is a general understanding of how an invasive organism might enter the region of interest, spread, and cause damage, and it is possible to find some proxy data to evaluate and map these invasion components in a geographic domain. However, given a dearth of prior knowledge about the invader's behavior in its new environment, it is extremely difficult to appropriately aggregate these individual components in a single risk map. Assessing the robustness to uncertainty is therefore an essential element in the analysis of risk. Linear weighted averaging techniques have been widely used to build aggregated pest risk maps, but these techniques depend upon (typically naïve) judgment about the relative importance of the individual risk components, and are further influenced by decisionmakers' perceptions regarding their severity. For this particular situation, our article has proposed a simpler data-driven technique for aggregating multiple risk components into a single risk map. The technique analyzes a risk map in the dimensions of its individual risk criteria and finds subsequent multiattribute efficient frontiers to delineate a combination of the most severe risks. Compared to a linear weighted averaging approach, the multiattribute frontier aggregation seems to be a better starting point in cases when the prior knowledge about an invasive pest is poor or lacking. In particular, the multiattribute frontier technique seems more robust to uncertainty.

\section{ACKNOWLEDGMENTS}

The authors extend their gratitude and thanks to Michael Tuffly (formerly with USDA Forest Service FHTET) for help with generating GIS data for the United States, Tedd Hogg, and David Price (Natural Resources Canada) for help with calculat- ing the Canadian CMI index. The participation of Frank Koch was supported by Research Joint Venture Agreement \#09-JV-11330146-088 between the USDA Forest Service, Southern Research Station, Asheville, NC and North Carolina State University.

\section{REFERENCES}

1. Boender GJ, Hagenaars TJ, Bouma A, Nodelijk G, Elbers ARM, de Jong MCM, van Boven M. Risk maps for the spread of highly pathogenic avian influenza in poultry. PLoS Computational Biology, 2007; 3(4):e71.

2. Venette RC, Kriticos DJ, Magarey R, Koch F, Baker RHA, Worner S, Gómez NN, McKenney D, Dobesberger EJ, Yemshanov D, De Barro P, Hutchison WD, Fowler G, Kalaris T, Pedlar J. Pest risk maps for invasive alien species: A roadmap for improvement. BioScience, 2010; 60:349-362.

3. Krist FJ, Sapio FJ, Tkacz BM. Mapping risk from forest insects and diseases. FHTET 2007-06. U.S. Dept. of Agriculture Forest Service, Forest Health Protection, Forest Health Technology Enterprise Team, Fort Collins, CO, 2007.

4. Magarey RD, Colunga-Garcia M, Fieselmann DA. Plant biosecurity in the United States: Roles, responsibilities, and information needs. BioScience, 2009; 59(10):875-884.

5. Tkacz B, Moody B, Castillo JV, Fenn ME. Forest health conditions in North America. Environmental Pollution, 2008; 155(3):409-425.

6. Stohlgren TJ, Schnase JL. Risk analysis for biological hazards: What we need to know about invasive species. Risk Analysis, 2006; 26:163-173.

7. Baker R, Cannon R, Bartlett P, Barker I. Novel strategies for assessing and managing the risks posed by invasive alien species to global crop production and biodiversity. Annals of Applied Biology, 2005; 146:177-191.

8. Linkov I, Loney D, Cormier S, Satterstrom FK, Bridges T. Weight-of-evidence evaluation in environmental assessment: Review of qualitative and quantitative approaches. Science of the Total Environment, 2009; 407:5199-5205.

9. Linkov I, Welle P, Loney D, Tkachuk A, Canis L, Kim JB, Bridges T. Use of multicriteria decision analysis to support weight of evidence evaluation. Risk Analysis, 2011, doi: 10.1111/j.1539-6924.2011.01585.x.

10. King R, Richardson C. Integrating bioassessment and ecological risk assessment: An approach to developing numerical water-quality criteria. Environmental Management, 2003; 31(6):795-809.

11. Feron V, van Vliet P, Notten W. Exposure to combinations of substances: A system for assessing health risks. Environmental Toxicology and Pharmacology, 2004; 18:215-222.

12. McDonald B, deBruyn A, Wernick B, Patterson L, Pellerin N, Chapman P. Design and application of a transparent and scalable weight-of-evidence framework: An example from Wabamun lake, Alberta, Canada. Integrated Environmental Assessment and Management, 2007; 3(4):476-483.

13. Landis W. The frontiers in ecological risk assessment at expanding spatial and temporal scales. Human and Ecological Risk Assessment, 2003; 9(6):1415.

14. Janssen R. Multiobjective Decision Support for Environmental Management. Dordrecht: Kluwer Academic Publishers, 1992.

15. Lahdelma R, Salminen P, Hokkanen J. Using multicriteria methods in environmental planning and management. Environmental Management, 2000; 26:595-605.

16. Linkov I, Satterstrom FK, Kiker G, Seager TP, Bridges T, Gardner KH, Rogers SH, Belluck DA, Meyer A. Multicriteria decision analysis: A comprehensive decision approach for 
management of contaminated sediments. Risk Analysis, 2006; 26:61-78.

17. Yatsalo BI, Kiker GA, Kim J, Bridges TS, Seager TP, Gardner K, Satterstrom FK, Linkov I. Application of multicriteria decision analysis tools to two contaminated sediment case studies. Integrated Environmental Assessment and Management, 2007; 3(2):223-233.

18. Steele K, Carmel Y, Cross J, Wilcox C. Uses and misuses of multicriteria decision analysis (MCDA) in environmental decision making. Risk Analysis, 2009; 29(1):26-33.

19. Figueira J, Greco S, Ehrgott M. (eds). Multiple Criteria Decision Analysis: State of the Art Surveys. New York: Kluwer Academic Publishers, 2005.

20. Moffett A, Sarkar S. Incorporating multiple criteria into the design of conservation area networks: A minireview with recommendations. Diversity and Distributions, 2006; 12: 135137.

21. Jiang H, Eastman JR. Application of fuzzy measures in multicriteria evaluation in GIS. International Journal of Geographical Information Science, 2000; 14(2):173-184.

22. Voogd H. Multi-Criteria Evaluations for Urban and Regional Planning. London, UK: Princeton University, 1983.

23. Canadian Food Inspection Agency (CFIA). Plant Health Risk Assessment: Draft Guidelines for Commodity-Specific Pest Risk Assessment. Nepean, Ontario: Plant Health Risk Assessment Unit, 2001.

24. USDA Forest Service Forest Health Technology Enterprise Team (FS FHTET). Invasive Pest Risk Maps. Mediterranean Pine Engraver - Orthotomicus erosus. 2010. Available at: http://www.fs.fed.us/foresthealth/technology/ invasives_orthotomicuserosus_riskmaps.shtml, Accessed on March 2010

25. Roy B, Bouyssou D. Comparison of decision-aid models applied to a nuclear power plant citing example. European Journal of Operational Research, 1986; 25:200-215.

26. Brans JP, Vincke Ph, Mareschal B. How to select and how to rank projects: The PROMETHEE method. European Journal of Operational Research, 1986; 24(2):228-238.

27. Saaty TL. The Analytic Hierarchy Process. New York: McGraw Hill, 1980.

28. Redpath S, Arroyo B, Leckie F, Bacon P, Bayfield N, Gutiérrez R, Thirgood S. Using decision modeling with stakeholders to reduce human-wildlife conflict: A raptor-grouse case study. Conservation Biology, 2004; 18:350-359.

29. Von Winterfeldt D, Edwards W. Decision Analysis and Behavioural Research. Cambridge, MA: Cambridge University Press, 1986.

30. Andrews CJ, Hassenzahl DM, Johnson BB. Accommodating uncertainty in comparative risk. Risk Analysis, 2004; 24:13231335.

31. Keeney RL, Raiffa H. Decisions with multiple objectives: Preferences and value tradeoffs. New York: John Wiley \& Sons, 1976

32. Florig HK, Morgan MG, Morgan KM, Jenni KE, Fischhoff B, Fischbeck PS, De Kay ML. deliberative method for ranking risks (I): Overview and test bed development. Risk Analysis, 2001; 21:913-922.

33. Morgan KM, Florig HK, De Kay ML, Fischbeck PS. Categorizing risks for risk ranking. Risk Analysis, 2000; 20: $49-58$.

34. Hadar J, Russel WR. Rules for ordering uncertain prospects. American Economic Review, 1969; 59:25-34.

35. Levy H, Wiener Z. Stochastic dominance and prospect dominance with subjective weighting functions. Journal of Risk and Uncertainty, 1998; 16(2):147-163.

36. Yager R. On ordered weighted averaging aggregation operators in multi-criteria decision making. IEEE Transactions on Systems, Man, and Cybernetics, 1988; 8: 183-190.
37. Eastman JR, Jiang H. Fuzzy measures in multi-criteria evaluation. Pp. 527-534 in Proceedings of the Second International Symposium on Spatial Accuracy Assessment in Natural Resources and Environmental Studies, May 21-23, 1995, Fort Collins, $\mathrm{CO}$.

38. Anagnostopoulos K, Doukas H, Psarras J. A linguistic multicriteria analysis system combining fuzzy sets theory, ideal and anti-ideal points for location site selection. Expert Systems with Applications, 2008; 35(4):2041-2048.

39. Linkov I, Varghese A, Jamil D, Seager TP, Kiker G, Bridges T. Multi-criteria decision analysis: A framework for structuring remedial decisions at contaminated sites. Pp. 15-54 in Linkov I, Ramadan A (eds). Comparative Risk Assessment and Environmental Decision Making. Dordrecht, The Netherlands: Kluwer, 2004.

40. Pareto V. Manual of Political Economy. New York: Augustus M. Kelley Publishers, 1971. Translated from 1927 French edition by Ann S. Schwier.

41. Charnes A, Cooper WW, Rhodes E. Measuring the efficiency of decision making units. European Journal of Operational Research, 1978; 2:429-444.

42. Barr RS, Seiford LM, Siems TF. An envelopment-analysis approach to measuring the managerial efficiency of banks. Annals of Operations Research, 1993; 45:1-19.

43. Barr RS, Durchholz ML, Seiford L. Peeling the DEA Onion: Layering and Rank-Ordering DMUs Using Tiered DEA; 2000. Available at: http://faculty.smu.edu/barr/pubs/layer.pdf, Accessed on June 5, 2011.

44. Charnes A, Cooper WW. Preface to topics in data envelopment analysis. Annals of Operations Research, 1985; 2:59-94.

45. Papadimitriou C, Yannakakis M. Multiobjective Query Optimization. Pp. 52-59 in PODS 2001 Proceedings of the 20th ACM SIGMOD-SIGACT-SIGART Symposium on Principles of database systems. New York: ACM, 2001.

46. Borzsonyi S, Kossmann D, Stocker K. The Skyline Operator. IEEE Conference on Data Engineering, 2001; Paper \# 235, pp. 421-430, Heidelberg, Germany.

47. Kossmann D, Ramsak F, Rost S. Shooting stars in the sky: An online algorithm for skyline queries. Very Large Databases (VLDB), 2002: 275-286.

48. McLain DH. Drawing contours from arbitrary data points. Computer Journal, 1974; 17(4):318-324.

49. Steuer RE. Multiple Criteria Optimization. New York: Wiley, 1986.

50. Green PJ, Silverman BW. Constructing the convex hull of a set of points in the plane. Computer Journal, 1979; 22(3): 262266.

51. Petitjean P, Saporta G. On the performance of peeling algorithms. Applied Stochastic Models and Data Analysis, 1992; 9:91-98.

52. Godfrey P, Shipley R, Gryz J. Algorithms and analyses for maximal vector computation. VLDB Journal, 2007; 16(1):528.

53. Goldberg DE. Genetic Algorithms in Search, Optimization, and Machine Learning. Reading, MA: Addison-Wesley Publ. Co., 1989.

54. Yemshanov D, Koch FH, Ben-Haim Y, Smith WD. Detection capacity, information gaps and the design of surveillance programs for invasive forest pests. Journal of Environment management, 2010; 91:2535-2546.

55. Jacquiot C. Tumors caused by Agrilus biguttatus Fab. attacks on the stems of oak trees. Marcellia, 1976; 39:61-67.

56. Moraal LG, Hilszczanski J. Agrilus biguttatus (Col.: Buprestidae) in relation with oak decline. Pp. 219-225 in Oszako T, Delatour C (eds). Recent Advances on Oak Health in Europe. Warsaw: Forest Research Institute, 2000.

57. Vansteenkiste D, Tirry L, Van Acker J, Stevens M. Predispositions and symptoms of Agrilus borer attack in declining oak trees. Annals of Forest Science, 2004; 61:815-823. 
58. Thomas FM, Blanks R, Hartmann G. Abiotic and biotic factors and their interactions as causes of oak decline in Central Europe. Forest Pathology, 2002; 32:277-307.

59. Ciesla W. EXFOR Database Pest Report: Agrilus biguttatus. USDA Forest Service. Available at: http://spfnic.fs.fed.us/ exfor/data/pestreports.cfm? pestidval=154\&langdisplay $=$ english, Accessed on April 2010.

60. Davis EE, French S, Venette RC. Mini Risk Assessment Metallic Beetle: Agrilus biguttatus Fabricius [Coleoptera: Buprestidae], 2005. Available at: http://www. aphis.usda.gov/plant_health/plant_pest_info/pest_detection/ downloads/pra/abiguttatuspra.pdf, Accessed on January 2010.

61. Hogg EH. Temporal scaling of moisture and the forestgrassland boundary in western Canada. Agricultural and Forest Meteorology, 1997; 84:115-122.

62. Willmott CJ, Feddema JJ. A more rational climatic moisture index. Professional Geographer, 1992; 44(1): 84-87.

63. USDA Forest Service (USDA FS). Forest Inventory and Analysis Database: Database Description and Users Guide Version 3.0. U.S. Department of Agriculture, Forest Service, Forest Inventory and Analysis Program, 2007. Available at: http://www.fia.fs.fed.us/tools-data/docs/pdfs/ FIADB_user\%20guide\%203-0_P3_6_01_07.pdf, Accessed on November 2009.

64. Gillis MD. Canada's national forest inventory, responding to current information needs. Environmental Monitoring and Assessment, 2001; 67:121-129.

65. Little EL, Jr. Atlas of United States Trees, Volume 1, Conifers and Important Hardwoods: Misc. Pub. 1146. Washington, DC: U.S. Department of Agriculture, 1971.

66. Environmental Systems Research Institute (ESRI) ARC/INFO Workstation. Ver. 9.2. Redlands, CA, 2006.

67. Statistics Canada (StatsCan). Population and dwelling counts. Census subdivisions (CSDs) - Municipalities. Data tables, 2008. Available at: http://www12.statcan.ca/censusrecensement/2006/dp-pd/hlt/97-550/Index.cfm?TPL=P2C\& Page $=$ SUB $\&$ LANG $=$ Eng $\& T=300$, Accessed on October 2009.

68. Statistics Canada (StatsCan). Census Geography, 2005. Road Network File 2005 - 92-500-X. Available at: http://geodepot. statcan.ca/Diss/2006Dissemination/Data/FRR_RNF_e.cfm, Accessed on October 2009.

69. Ben-Haim Y. Info-gap Decision Theory: Decisions Under Severe Uncertainty. 2nd edition, Oxford, UK: Academic Press, 2006.

70. Yemshanov D, Koch FH, Ben-Haim Y, Smith WD. Robustness of risk maps and survey networks to knowledge gaps about a new invasive pest. Risk Analysis, 2010; 30: 261-276.

71. Breiman L. Machine Learning. Wald Lecture I. University of California. Berkeley, CA: Statistics Department, 2002. Available at: http://stat-www.berkeley.edu/users/ breiman/wald2002-1.pdf, Accessed on September 2009.

72. Kung HT, Luccio F, Preparata FP. On finding the maxima of a set of vectors. Journal of the ACM, 1975; 22(4):469476.

73. Rhee C, Dhall SK, Lakshmivarahan S. The minimum weight dominating set problem for permutation graphs is in NC. Journal of Parallel and Distributed Computing, 1995; 28(2):109-112.

74. Tan K-L, Eng P-K, Ooi BC. Efficient progressive skyline computation. Pp. 301-310 in VLDB '01: Proceedings of the $27^{\text {th }}$ International Conference on Very Large Data Bases. San Francisco, CA: Morgan Kaufmann Publishers Inc., 2001.

75. Papadias D, Tao Y, Fu G, Seeger B. An optimal and progressive algorithm for skyline queries. Pp. 467-478 in Proc 2003 ACM SIGMOD International Conference on Management of Data. San Diego, CA, 2003.

76. Yemshanov D, Koch FH, Lyons B, Ducey M, Koehler K. A dominance-based approach to map risks of ecological invasions in the presence of severe uncertainty. Diversity and Distributions, 2012; 18:33-46.

77. Yemshanov D, Koch FH, Ducey M, Koehler K. Mapping ecological risks with a portfolio-based technique: Incorporating uncertainty and decision-making preferences. Diversity and Distributions, 2013: 19, in press.

\section{SUPPORTING INFORMATION}

Additional supporting information may be found in the online version of this article at the publisher's website:

Appendix 1. Maps of the individual risk criteria: (A) drought index; (B) amount of susceptible host (oaks, Quercus spp); (C) pest introduction potential. The criteria values were normalized to a $0-1$ range.

Appendix 2. Map of the Euclidean distance, $D_{j}$, between the MAF and LWA robustness curves, for each location (i.e., map cell) $j$. 